\title{
openheart Dietary fats, blood pressure and artery health
}

James J DiNicolantonio, ${ }^{\circledR}$ James OKeefe ${ }^{\odot}$

To cite: DiNicolantonio JJ, OKeefe J. Dietary fats, blood pressure and artery health. Open Heart 2019;6:e001035. doi:10.1136/ openhrt-2019-001035

Accepted 13 June 2019
Check for updates

(C) Author(s) (or their employer(s)) 2019. Re-use permitted under CC BY-NC. No commercial re-use. See rights and permissions. Published by BMJ.

Preventive cardiology, University of Missouri-Kansas City, Saint Lukes Mid America Heart Institute, Kansas City, Missouri, USA

Correspondence to Dr James J DiNicolantonio; jjdinicol@gmail.com
Nitric oxide is an important endogenously made vasodilator that has numerous antiatherosclerotic properties. Many lines of evidence suggest that a lack of nitric oxide can lead to hypertension and atherosclerotic plaque formation. ${ }^{1}$ Nitric oxide synthase (NOS) is the enzyme that produces nitric oxide in the body. The two main inhibitors of NOS are asymmetric dimethyl arginine (ADMA) and NG-monomethyl arginine. These NOS inhibitors are metabolised and inactivated by the enzyme dimethyarginine dimethylamine hydrolase (DDAH). Thus, inhibition of DDAH can lead to a reduction in NOS.

The oxidation of the omega- 6 fat linoleic acid can form the highly reactive aldehyde called 4-hydroxy-2-nonenal (4-HNE), which has been noted to reduce nitric oxide generation from endothelial cells by reducing the activity of the DDAH enzyme. ${ }^{2}$ An inhibition of DDAH increases the NOS inhibitor ADMA in endothelial cells causing endothelial NOS (eNOS) 'uncoupling' and increased production of superoxide rather than nitric oxide. Since ADMA competitively inhibits NOS and is an independent cardiovascular risk factor this suggests that consuming isolated forms of linoleic acid, such as refined omega- 6 vegetable oils, may lead to elevations in blood pressure and potentially hypertension. ${ }^{3}$ Moreover, linoleic acid inhibits insulin signalling and eNOS activation in the vasculature both of which are implicated in hypertension. ${ }^{4}$

Conditions with reduced NOS activity coincide with disease states that are hallmarked by an increase in oxidised lipids, including oxidised linoleic acid. When LDL becomes oxidised, this is initially from the oxidised linoleic acid contained within the LDL, which forms the highly reactive aldehyde 4-HNE, levels of which coincide with increased atherosclerotic progression. ${ }^{2}$ Since oxidised LDL is found in atherosclerotic lesions in animals and in humans ${ }^{5}$ and can directly cause endothelial dysfunction via reductions in nitric oxide, the ability of dietary linoleic acid to increase LDL susceptibility to oxidation suggests that consuming refined vegetable oils high in linoleic acid may increase the risk of hypertension as well as atherosclerosis. ${ }^{6}$

\section{EXTRA VIRGIN OLIVE OIL (EV00) VERSUS OMEGA-6 VEGETABLE OIL}

When added on top of a monounsaturated fatty acid (MUFA)-rich diet, olive oil has been found to have a greater antihypertensive effect in patients with normocholesterolaemia and hypercholesterolaemia $(-10 / 10$ $\mathrm{mm} \mathrm{Hg}$ and $-7 / 6 \mathrm{~mm} \mathrm{Hg})$ even when compared with high-oleic sunflower oil $(-6 / 5$ $\mathrm{mm} \mathrm{Hg}$ and $-2 / 0.5 \mathrm{~mm} \mathrm{Hg}$, respectively). ${ }^{7}$ One randomised study in 23 patients with hypertension (baseline blood pressure was 134/90 mm Hg) placed patients on a MUFA diet $(17.2 \%$ MUFA, $3.8 \%$ polyunsaturated fatty acids (PUFA) ) or an omega-6 PUFA diet (10.5\% MUFA, $10.5 \%$ PUFA) for 6 months. ${ }^{8}$ Study participants were recommended to consume $40 \mathrm{~g}$ of EVOO or sunflower oil (30 $\mathrm{g}$ was recommended per day in women) with the oils being added to the diet after the cooking of foods. Patients were then crossed over to the other diet. At the end of the MUFA diet, resting blood pressure was significantly lower $(127 / 84 \mathrm{~mm} \mathrm{Hg})$ compared with the omega-6 PUFA diet $(135 / 90 \mathrm{~mm} \mathrm{Hg}$, $\mathrm{p}=0.05$ systolic, $\mathrm{p}=0.01$ diastolic). The antihypertensive medication dosage was also significantly reduced by $48 \%$ with the MUFA diet but non-significantly ( $4 \%$ reduction) with the omega-6 PUFA diet $(p<0.005$ for the difference). Moreover, eight patients on the MUFA diet no longer needed any antihypertensive therapy by the end of the study, whereas, all patients receiving the omega-6 PUFA diet required antihypertensive treatment despite two patients at baseline who initially did not need antihypertensive medications prior to the omega-6 PUFA diet. It was concluded that the use of EVOO, '...markedly lowers daily antihypertensive dosage requirement, 
Box 1 Potential mechanisms implicating linoleic acid from omega- 6 vegetable oils and hypertension

- May reduce nitric oxide generation and increase superoxide production from endothelial cells by reducing dimethyarginine dimethylamine hydrolase enzyme activity and increasing asymmetric dimethyl arginine. ${ }^{2}$

- Inhibits insulin signalling and endothelial nitric oxide synthase activation in the vasculature. ${ }^{4}$

- Increased oxidised low-density lipoprotein, which can directly cause endothelial dysfunction and hypertension. ${ }^{6}$

- Increased production of vasoconstricting eicosanoids. ${ }^{10}$

- Reduced incorporation of eicosapentaenoic acid/docosahexaenoic acid into cellular membranes. ${ }^{19}$

- Increased chronic low-grade inflammation and endothelial cell activation/dysfunction. $^{27} 28$

possibly through enhanced nitric oxide levels stimulated by polyphenols' 8

\section{OMEGA-3 FISH OIL VERSUS OMEGA-6 VEGETABLE OIL}

In a 10-week randomised study, $6 \mathrm{~g}$ of fish oil per day (5100 mg of eicosapentaenoic acid (EPA)/docosahexaenoic acid (DHA)) significantly lowered blood pressure $(-4.6 /-3.0 \mathrm{~mm} \mathrm{Hg})$ in those with previously untreated mild hypertension. ${ }^{9}$ This benefit was not found with $6 \mathrm{~g}$ of corn oil. Indeed, the blood pressure difference between the fish oil and corn oil groups, after adjusting for other covariates, was $-6.4 /-2.8 \mathrm{~mm} \mathrm{Hg}$ in favour of the fish oil. ${ }^{9}$ There was also a borderline significant increase in standing arterial pressure after 10 weeks of supplementation with corn oil compared with baseline $(+2.00 \mathrm{~mm}$ $\mathrm{Hg}, \mathrm{p}=0.055)$. Moreover, compared with baseline, the standing blood pressure increased from 143.6/97.8 mm $\mathrm{Hg}$ to $144.9 / 98.9 \mathrm{~mm} \mathrm{Hg}$ and sitting blood pressure went from 142.8/94.6 to 144/94.4 mm Hg with corn oil supplementation. ${ }^{9}$ A diet high in omega- 6 can increase the production of vasoconstricting eicosanoids which may promote increases in blood pressure. ${ }^{10}$ Thus, more data is needed to understand the effects of omega- 6 rich vegetable oils such as corn oil on blood pressure. Box 1 summarises the potential mechanisms implicating linoleic acid from omega- 6 vegetable oils and hypertension.

\section{THE BENEFITS OF MARINE OMEGA-3S ON BLOOD PRESSURE}

Fish oil supplementation has been found to reduce blood pressure and normalise the hypercoagulable state in patients who are obese, hypertensive and dyslipidaemic. ${ }^{11}$ Fish oil leads to a similar reduction in blood pressure in both patients without diabetics $(-12.7 \mathrm{~mm} \mathrm{Hg} /-7.9 \mathrm{~mm}$ $\mathrm{Hg}$; baseline blood pressure 158.7/80.8 $\mathrm{mm} \mathrm{Hg}$ down to $146 / 72.9 \mathrm{~mm} \mathrm{Hg}, \mathrm{p}<0.001)$ and patients with diabetic hypertension (-15.7/-7.6 mm Hg; baseline blood pressure $157.6 / 83.2 \mathrm{~mm} \mathrm{Hg}$ going down to $141.9 / 75.6 \mathrm{~mm}$ $\mathrm{Hg}, \mathrm{p}<0.001)$. Thus, fish oil can reduce blood pressure by $12 / 7 \mathrm{~mm} \mathrm{Hg}$ or more, making marine omega-3 supplementation an extremely potent antihypertensive especially in certain patient populations. Moreover, fish oil reduces platelet aggregation in non-diabetics $(4.2 \%$ vs $12.1 \%, \mathrm{p}<0.001)$. Patients with diabetes may need larger dose of omega-3s compared with patients without diabetics in order to improve their hypercoagulable state. ${ }^{12}$ The same may apply to patients with metabolic syndrome. ${ }^{13}$

In one double-blind, placebo-controlled trial, fish oil (containing 2 g of omega-3s) significantly improved endothelial function in normoglycemic offspring of type 2 diabetics. ${ }^{14}$ Fish oil also reduced markers of inflammation (tumour necrosis factor-alpha, interleukin-6, high sensitivity-C-reactive protein, vascular cell adhesion molecule, intercellular adhesion molecule and E-selectin) and tended to improve adiponectin levels. Since the offspring of type 2 diabetics generally have endothelial dysfunction and chronic inflammation, this patient population may particularly benefit from supplementing with the EPA and DHA. Considering that endothelial dysfunction is thought to be one of the initial steps in the formation of atherosclerotic plaque, marine omega-3s may also be useful for reducing the risk of cardiovascular events. In summary, the endothelium becomes healthier when the offspring of patients with type 2 diabetes supplement with fish oil. This may be due to a reduction in inflammation.

Another randomised double-blind placebo-controlled trial in 59 overweight, mildly hyperlipidaemic men found that $4 \mathrm{~g}$ of DHA per day, as compared with EPA, for 6 weeks improved forearm blood flow in response to acetylcholine infusion and coinfusion of acetylcholine with $\mathrm{N}$ :(G)-monomethyl-L-arginine versus placebo (olive oil). DHA also enhanced the dilatory responses to sodium nitroprusside and reduced the constrictor response to norepinephrine. The authors concluded, 'relative to placebo, DHA, but not EPA, enhances vasodilator mechanisms and attenuates constrictor responses in the forearm microcirculation. Improvements in endothelium-independent mechanisms appear to be predominant and may contribute to the selective blood pressure-lowering effect observed with DHA compared with EPA in humans'. ${ }^{15}$ Indeed, in another study, DHA but not EPA was able to reduce postprandial arterial stiffness after a high-fat test meal. ${ }^{16}$ Thus, DHA may have better antihypertensive and antiatherosclerosis effects compared with EPA.

A 24-week randomised double-blind placebo-controlled trial in 60 patients with systemic lupus erythematosus showed that $3 \mathrm{~g}$ of omega-3 PUFAs significantly improved disease activity, brachial artery endothelial function, and oxidative stress. The authors concluded, 'Low-dose dietary supplementation with omega-3 fish oils in systemic lupus erythematosus not only has a therapeutic effect on disease activity but also improves endothelial function and reduces oxidative stress and may therefore confer cardiovascular benefits'. ${ }^{17}$ Similar findings of improved large artery endothelial function were found with omega-3 PUFAs (4 g/day) in patients with hypercholesterolaemia. ${ }^{18}$ 
A meta-analysis of 31 placebo-controlled studies found a dose-dependent reduction in blood pressure with fish oil intake $(-1.3 /-0.7 \mathrm{~mm} \mathrm{Hg}$ at doses $<3 \mathrm{~g} /$ day; $-2.9 /-1.6$ $\mathrm{mm} \mathrm{Hg}$ at 3.3 to $7 \mathrm{~g} /$ day and $-8.1 /-5.8 \mathrm{~mm} \mathrm{Hg}$ at $15 \mathrm{~g} /$ day) with an average reduction of $-3.0 /-1.5 \mathrm{~mm} \mathrm{Hg}{ }^{19}$ However, at least $3.3 \mathrm{~g} /$ day of omega-3s was needed to provide a significant reduction in blood pressure and this benefit seems to be strongest in patients with hypertension $(-3.4 / 2.0 \mathrm{~mm} \mathrm{Hg}$, mean dose of $5.6 \mathrm{~g}$ /day), hyperlipidaemia $(-4.4 /-1.1 \mathrm{~mm} \mathrm{Hg}$, mean dose of $4 \mathrm{~g} /$ day) and especially atherosclerosis $(-6.3 /-2.9 \mathrm{~mm} \mathrm{Hg})$. A second meta-analysis of 36 randomised trials confirmed that fish oil (median dose $3.7 \mathrm{~g} /$ day) significantly reduces blood pressure by $-2.1 /-1.6 \mathrm{~mm} \mathrm{Hg} .{ }^{20}$ And another meta-analysis of 30 randomised trials showed that EPA+DHA (median dose of $3.5 \mathrm{~g} /$ day) reduces heart rate by 1.6 beats per minute versus placebo $(\mathrm{p}=0.002)$ and by 2.5 beats per minute in trials with a duration of $\geq 12$ weeks or in those with a baseline heart rate $\geq 69$ beats per minute. ${ }^{21}$ Another meta-analysis of 16 randomised controlled trials found that omega-3 PUFAs (ranging from 0.45 to 4.5 $\mathrm{g} /$ day) over a median of 56 days significantly increases flow-mediated dilation indicating an improvement in endothelial function. ${ }^{22}$ These results were confirmed in overweight patients with dyslipidaemia and type 2 diabetes. ${ }^{23}$ Another meta-analysis of controlled clinical trials found that omega-3 PUFA (at doses above $3 \mathrm{~g}$ /day) significantly lowers blood pressure. Indeed, in normotensives, the average blood pressure reduction was $-1 /-0.5$ $\mathrm{mm} \mathrm{Hg}$ and in untreated hypertensives, the reduction in blood pressure was much greater at $-5.5 /-3.5 \mathrm{~mm} \mathrm{Hg} .{ }^{24}$ DHA, as compared with EPA, may have a greater ability to reduce blood pressure and heart rate through improvements in vascular function. ${ }^{25}$

\section{ALPHA-LINOLENIC ACID}

Alpha-linolenic acid (ALA) is naturally found in foods such as linseed (flaxseed), legumes, nuts (walnuts and chestnuts), spinach and citrus fruits. While there is very limited data with ALA and blood pressure, one observational study showed that for each $1 \%$ increase in ALA content in adipose tissue there was a decrease of $5 \mathrm{~mm}$ $\mathrm{Hg}$ in the systolic, diastolic and composite mean arterial blood pressure. ${ }^{26}$ The authors concluded, '... it is the linolenic (ALA) rather than the linoleic acid (LA) content of the diet that is negatively related to blood pressure'. ${ }^{26}$

\section{CONCLUSION}

In summary, the evidence is unclear whether omega-6 vegetable oils high in linoleic acid increase blood pressure. However, there is some evidence that if linoleic acid is coming from industrial seed oils, there may be an increase in blood pressure as well as cardiovascular disease/mortality. The marine omega-3s EPA and DHA, extra virgin olive oil and possibly the parent omega-3 ALA may reduce the risk hypertension and cardiovascular disease. The antihypertensive effect of DHA may outweigh that of EPA which may due to a greater ability to improve endothelial function and arterial vasodilation.

Contributors Both authors contributed to the final manuscript.

Funding The authors have not declared a specific grant for this research from any funding agency in the public, commercial or not-for-profit sectors.

Competing interests JJD is the author of The Salt Fix, Superfuel and The Longevity Solution. J0 has an ownership interest in CardioTabs a company that sells fish oil.

Patient consent for publication Not required.

Provenance and peer review Not commissioned; externally peer reviewed.

Open access This is an open access article distributed in accordance with the Creative Commons Attribution Non Commercial (CC BY-NC 4.0) license, which permits others to distribute, remix, adapt, build upon this work non-commercially, and license their derivative works on different terms, provided the original work is properly cited, appropriate credit is given, any changes made indicated, and the use is non-commercial. See: http://creativecommons.org/licenses/by-nc/4.0/.

\section{REFERENCES}

1. Förstermann $U$, Xia N, Li H. Roles of vascular oxidative stress and nitric oxide in the pathogenesis of atherosclerosis. Circ Res 2017;120:713-35.

2. Pope AJ, Druhan L, Guzman JE, et al. Role of DDAH-1 in lipid peroxidation product-mediated inhibition of endothelial NO generation. Am J Physiol Cell Physiol 2007;293:C1679-C1686.

3. Chen L, Zhou J-P, Kuang D-B, et al. 4-HNE increases intracellular ADMA levels in cultured HUVECs: evidence for miR-21-dependent mechanisms. PLoS One 2013;8:e64148.

4. Wang XL, Zhang L, Youker K, et al. Free fatty acids inhibit insulin signaling-stimulated endothelial nitric oxide synthase activation through upregulating PTEN or inhibiting Akt kinase. Diabetes 2006;55:2301-10.

5. Ylä-Herttuala S, Palinski W, Rosenfeld ME, et al. Evidence for the presence of oxidatively modified low density lipoprotein in atherosclerotic lesions of rabbit and man. J Clin Invest 1989;84:1086-95.

6. Gradinaru D, Borsa C, lonescu C, et al. Oxidized LDL and NO synthesis--Biomarkers of endothelial dysfunction and ageing. Mech Ageing Dev 2015;151:101-13.

7. Ruíz-Gutiérrez V, Muriana FJ, Guerrero A, et al. Plasma lipids, erythrocyte membrane lipids and blood pressure of hypertensive women after ingestion of dietary oleic acid from two different sources. J Hypertens 1996;14:1483-90.

8. Ferrara LA, Raimondi AS, d'Episcopo L, et al. Olive oil and reduced need for antihypertensive medications. Arch Intern Med 2000;160:837-42.

9. Bønaa KH, Bjerve KS, Straume B, et al. Effect of eicosapentaenoic and docosahexaenoic acids on blood pressure in hypertension. A population-based intervention trial from the Troms $\varnothing$ study. N Engl J Med 1990;322:795-801.

10. Lahoz C, Alonso R, Ordovás JM, et al. Effects of dietary fat saturation on eicosanoid production, platelet aggregation and blood pressure. Eur J Clin Invest 1997;27:780-7.

11. Yosefy C, Viskoper JR, Laszt A, et al. The effect of fish oil on hypertension, plasma lipids and hemostasis in hypertensive, obese, dyslipidemic patients with and without diabetes mellitus. Prostaglandins Leukot Essent Fatty Acids 1999;61:83-7.

12. DiNicolantonio JJ, O'Keefe JH, McCarty MF. Targeting aspirin resistance with nutraceuticals: a possible strategy for reducing cardiovascular morbidity and mortality. Open Heart 2017;4:e000642.

13. Simpson HC, Mann JI, Meade TW, et al. Hypertriglyceridaemia and hypercoagulability. Lancet 1983;1:786-90.

14. Rizza S, Tesauro M, Cardillo C, et al. Fish oil supplementation improves endothelial function in normoglycemic offspring of patients with type 2 diabetes. Atherosclerosis 2009;206:569-74.

15. Mori TA, Watts GF, Burke V, et al. Differential effects of eicosapentaenoic acid and docosahexaenoic acid on vascular reactivity of the forearm microcirculation in hyperlipidemic, overweight men. Circulation 2000;102:1264-9.

16. McManus S, Tejera N, Awwad K, et al. Differential effects of EPA versus DHA on postprandial vascular function and the plasma oxylipin profile in men. J Lipid Res 2016;57:1720-7.

17. Wright SA, O'Prey FM, McHenry MT, et al. A randomised interventional trial of omega-3-polyunsaturated fatty acids on 
endothelial function and disease activity in systemic lupus erythematosus. Ann Rheum Dis 2008;67:841-8.

18. Goodfellow J, Bellamy MF, Ramsey MW, et al. Dietary supplementation with marine omega-3 fatty acids improve systemic large artery endothelial function in subjects with hypercholesterolemia. J Am Coll Cardiol 2000;35:265-70.

19. Morris MC, Sacks F, Rosner B. Does fish oil lower blood pressure? A meta-analysis of controlled trials. Circulation 1993;88:523-33.

20. Geleijnse JM, Giltay EJ, Grobbee DE, et al. Blood pressure response to fish oil supplementation: metaregression analysis of randomized trials. J Hypertens 2002;20:1493-9.

21. Mozaffarian D, Geelen A, Brouwer IA, et al. Effect of fish oil on heart rate in humans: a meta-analysis of randomized controlled trials. Circulation 2005;112:1945-52.

22. Wang $Q$, Liang $X$, Wang $L$, et al. Effect of omega-3 fatty acids supplementation on endothelial function: a meta-analysis of randomized controlled trials. Atherosclerosis 2012;221:536-43.
23. Egert S, Stehle P. Impact of n-3 fatty acids on endothelial function: results from human interventions studies. Curr Opin Clin Nutr Metab Care 2011;14:121-31.

24. Appel LJ, Miller ER, Seidler AJ, et al. Does supplementation of diet with 'fish oil' reduce blood pressure? A meta-analysis of controlled clinical trials. Arch Intern Med 1993;153:1429-38.

25. Mori TA. Omega-3 fatty acids and hypertension in humans. Clin Exp Pharmacol Physiol 2006;33:842-6.

26. Berry EM, Hirsch J. Does dietary linolenic acid influence blood pressure? Am J Clin Nutr 1986;44:336-40.

27. Marchix J, Choque B, Kouba M, et al. Excessive dietary linoleic acid induces proinflammatory markers in rats. $J$ Nutr Biochem 2015;26:1434-41.

28. Hennig B, Toborek M, McClain CJ. High-energy diets, fatty acids and endothelial cell function: implications for atherosclerosis. J Am Coll Nutr 2001;20(2 Suppl):97-105. 